\title{
The Use of Emotionally Colored Words in English E-Headlines
}

\section{Kristine Harutyunyan, Hayk Danielyan}

Yerevan State University

\begin{abstract}
E-headlines play an important role in shaping our interest towards reading different online articles and news. There are a lot of strategies and techniques of attracting the readers' attention and one of them is the use of emotionally colored words. The aim of the present paper is to define the characteristics of emotionally colored words as lexical phenomena and to analyze special emotional word colorings in English e-headlines that are deliberately used to make an immediate impact on the readers' choice. The famous western electronic newspapers and magazines like "Time", "The Telegraph", "The Guardian", "The New York Times" and "The Sun" make the source platform of the current investigation.
\end{abstract}

Key words: e-headlines, emotionally colored words, electronic news, interjections, evaluation, intensifiers, word coloring.

\section{Introduction}

Electronic news headlines are of great importance in providing quality news. Their function is to briefly inform the reader what the body that follows is about, thus, news reporters bear a great responsibility to draw the readers' attention to what is in fact trustful and worthy information. As the media world grows bigger with a snowball effect over the years, the necessity to feed the audience's curiosity becomes indispensable. Lots of skills and techniques are being implemented by the electronic news reporters to headline the materials and make them more attractive for reading.

Headlines in newspapers greatly vary from the ones on electronic news. Electronic headlines are separate from the article body and readers can only 
access the material by a hyperlink. In modern media world it is challenging to attract a great amount of readers by just a limited amount of information in headings. Thus, electronic news reporters are inclined to use eye-snaring words to give intriguing information to readers about the material and make them interested to continue the reading. Electronic headlines should be impressive and emotional to gain more attention, therefore online news reporters often use words with emotional colorings to headline their articles. It is especially common in British and American electronic newspapers and magazines which are deservedly considered to be the best quality news sources in the world.

Emotionally colored words have their lexical peculiarities and distinctive characteristics. Arnold (1986) distinguishes emotionally colored words from emotionally neutral ones and gives them a certain classification. Interjections, intensifiers and the so-called evaluating words are considered to bear emotional colorings. Ginzburg (1979) also adds to the list some dialectal and slang words, and states that some sounds themselves may carry emotional colorings.

The use of emotive vocabulary in the headlines of online articles is a very popular technique which satisfies the requirements of modern understanding from news attractiveness perspective. Emotionally colored words are widely used in electronic headlines mostly covering political and world issues. Our intention is to gather up certain electronic headlines with emotionally colored words from the popular western online newspapers and magazines and to study their effects on arousing the readers' curiosity and leveling up news quality.

\section{The Distinctive Peculiarities of Emotionally Colored Words}

The emotional coloring of a word is a lexical phenomenon and represents one of the components of shaping the emotive quality of discourse. Emotionally colored words have distinctive function in speech and language. Jakobson (1987) believes that the emotive function of language flavors to some extent all our utterances, on their phonic, grammatical and lexical levels.

Emotionally colored words are differentiated from emotionally neutral ones. Interjections are the most popular type of emotionally colored words. Interjections express emotions without naming them (Arnold, 1986): 'Eh', 
'Hmm', 'Oops', 'Phew', 'Whoa', 'Yoo-hoo'. The appropriateness of some interjections has evoked the necessity to use them as verbs over time, e.g. "The crowd boos the players" in a specific context means that the crowd expresses their intolerance or complaint towards the players. So, we can see that the emotionally colored expression closein the form of interjection satisfies the semantic requirement of a context. Besides, other parts of speech can also be used as interjections. The interjection "God!" can express the speaker's delight, surprise or fear but as a proper noun it may not bear the same emotional values. On the other hand, the interjection "damn" has the connotative coloring close to its corresponding verb. In the time of Shakespeare 'peace' as an interjection meant 'Silence!' (Arnold 1986). Thus, words belonging to different parts of speech can bear emotional colorings when used as interjections.

Another specific set of emotional words are intensifiers which convey special intensities to highlight the importance of what is expressed. Intensifiers are mainly expressed by adverbs or adverbial phrases (Arnold 1986). For instance, the adverb 'extremely', which often describes conditions with negative implications, has an intensifying positive connotation in the utterance "I am extremely lucky to know her". The use of intensifiers allows to dodge the common application of some emotionally neutral words, e.g. 'very funny' can be replaced by 'super funny'.

There are some sets of words that are seemingly devoid of emotional elements but may possess emotive implications. For an architect the word 'church' may not be implicated emotionally in the same way as for a religious person. Besides, some colloquial words may also carry more emotional colorings than their neutral versions, e.g. 'daddy' and 'mummy' are more emotional than 'father' and 'mother'. There is also a considerable number of emotionally colored dialectal and slang words (Ginzburg, 1979), e.g. 'chubby' - 'fatty' and 'lit' - 'exciting, excellent'.

Arnold (1986) also distinguishes the so-called evaluating words which not only can possess emotional colorings in the context but also specify them. They highlight speaker's intentions to mean specific implications. The word 'fox' can 
be used to describe a person who is cunning and even can make an adjective itself becoming 'foxy'.

At last, it is also researched (Ginzburg 1979) that some sounds themselves may carry emotional colorings. Sound forms may evoke associations connected with the things they denote. Sound cluster [on] in the word 'dong' is associable with the deep resonant sound of a large bell.

\section{Emotionally Colored Headlines in English Electronic News}

The world of media has a remarkable influence on our everyday life. The flow of information within online platforms has accelerating rates and people want to keep up with as many events as possible. Electronic news is mainly the best solution of staying up-to-date but quality news is a really big issue in this perspective. Electronic information (particularly electronic newspaper headlines) should be presented in such a manner as to minimize the amount of time required for acquisition by the user (Kingery \& Furuta 1997).

Electronic news headlines need to be compact but also should capture the readers' attention and compel them to read the body. They need to be economical and attractive to arouse the readers' curiosity and for this reason, article reporters of the famous western newspapers and magazines give the priority to the use of emotionally colored words to headline their materials. Headlines with emotional colorings mainly appear in political and world news. This technique is often used to add some flavor to daily repetitive news.

Electronic news article reporters often use the direct citation of a politician's speech to make the material more authentic and trustworthy.

\section{EU WHAT? Irish PM Leo Varadkar sparks anger by claiming the British people want a second Brexit referendum as he rejects Boris' deal (The Sun)}

The expression 'EU WHAT' has binary meaning cited from the Irish PM's speech. 'EU' is an interjection that represents the PM's attitude towards the matter and also stands for the initials of 'European Union' implicitly hinting the 
reporter's intentions to mention it. Another interpretation of the same event can be found in the headline of this online article:

Boris Johnson: 'I Love Europe' and Here Is My Plan to Leave It

(The New York Times)

In this case we seemingly deal with a direct citation as well but in fact these are Johnson's words from different parts of his speech. The use of Johnson's emotional words in the headline makes the reader even more eager to find out the details behind. Political news readers love drama and scandal and for the online news article reporters it is preferable to cite in the headline what is exciting and shocking.

There is a set of English electronic headlines that use words metaphorically to obtain the emotional impact in a specific context. Let us consider this headline on global health security topic:

Mission impossible? Creator of world's first 'bleeding' vegan burger predicts meat-free world by 2035

(The Telegraph)

Here 'bleeding' is associated with actual meat burgers and is used metaphorically to highlight the similarity between traditional and meat-free burgers. This technique of an emotional coloring of a headline focuses on human associations with the help of eye-snaring vocabulary. It captures the readers' attention by making an associative description.

Emotional colorings of headlines often highlight the importance of the matter discussed in the article. They help the reader to distinguish between everyday repetitive media 'junk' and an important issue to be paid attention to.

Pakistani Prime Minister Warns of 'Bloodbath' in Kashmir Region

(Time) 
The emotional word 'bloodbath' is not an ordinary use to inform the reader about a specific issue. It tells a lot about the emergency level of the matter and stimulates the reader's wish to reveal the actual story. An emotional story always requires a proper emotional heading and news article authors acquire the use of the words which primarily evoke emotional associations.

Electronic news headlines should be intriguing. They should offer exciting and shocking content. Celebrities are always in the center of attention of online news reporters. A celebrity's comment on anything can make the material a piece of fascinating news. Sometimes online news can be headlined with the use of profanity and swear words making it more emotional and attractive.

\section{Robert De Niro drops $f$-bomb on critics of anti-Trump stance}

(The Guardian)

In this case we deal with the initial letter of an actual swear word from De Niro's interview and an add-on word with really emotional associations. This word combination is not directly quoted but makes the headline even more emotional and eye-snaring.

\section{Conclusion}

Summing up the current research we may conclude that in English emotionally colored words are differentiated from emotionally neutral ones, and there are several lexical phenomena that possess affective connotations. We may conclude that emotionally colored words are often deliberately used in English electronic news headlines to arouse the readers' curiosity and compel them to read the body of the article. Headlines with emotional colorings often cover political and world topics. With the help of specific headlines of popular western newspapers and magazines we studied the impact of the use of emotionally colored words on the attractiveness of the material and the quality of the news.

\section{References:}

1. Arnold, I.V. (1986) The English Word. M.: Vyssaja Skola. 
2. Ginzburg, R.S. (1979) A Course in Modern English Lexicology. M.: Vyssaja Skola.

3. Jakobson, R. (1987) Language in Literature. Massachusetts: Harvard University Press.

4. Kingery, D. \& Furuta R. (1997) Skimming Electronic Newspaper Headlines: A Study of Typeface, Point Size, Screen Resolution and Monitor Size. Oxford: Pergamon Press.

\section{Sources of Data:}

1. Alex Matthews; The Sun. Available at: <https://www.thesun.co.uk/news /brexit/10056541/leo-varadkar-says-brits-want-second-brexit-vote/> [Accessed October 2019].

2. Anne Gulland; The Telegraph. Available at: <https://www. telegraph.co.uk/global-health/climate-and-people/mission-impossiblecreator-worlds-first-bleeding-vegan-burger/> [Accessed October 2019].

3. Foster Klug \& Jennifer Peltz; Time. Available at: <https://time.com/56 88224/pakistan-prime-minister-kashmir-india/>[AccessedOctober 2019].

4. Mark Landler \& Stephen Castle; The New York Times (accessed: 03.10.2019). Available at: <https://www.nytimes.com/2019/10/02/ world/europe/boris-johnson-brexit-eu.html> [Accessed October 2019].

5. Victoria Bekiempis; The Guardian. Available at: <https://www.theguardian. com/film/2019/sep/29/robert-de-niro-cnn-trump-fox-news >

[Accessed October 2019].

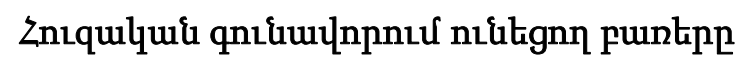

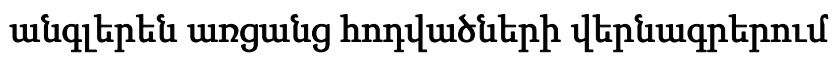

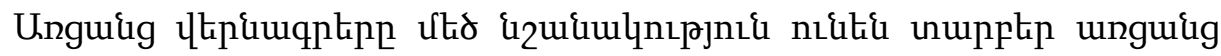

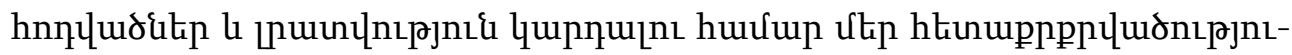

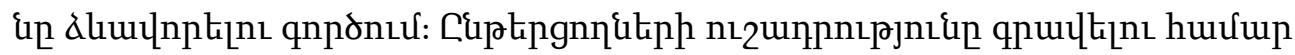

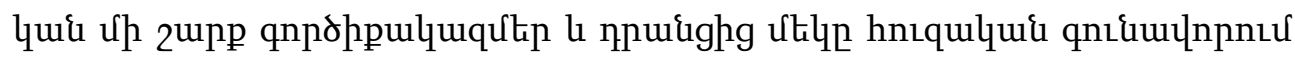

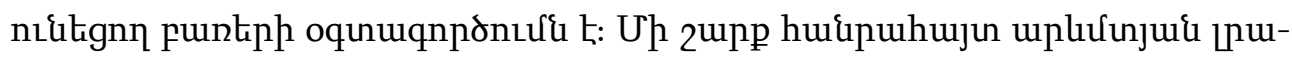




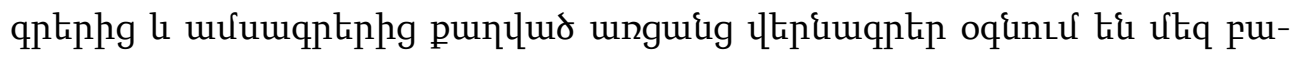

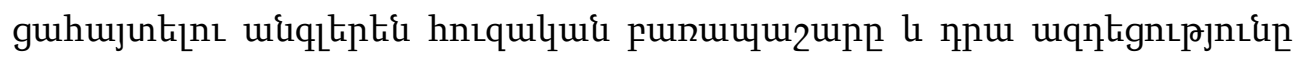

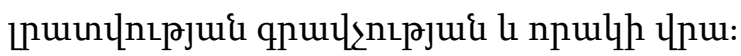

Received by the Editorial Board 08.10.2019

Recommended for publication by the reviewers 26.11.2019

Accepted for print 03.02.2020 